\title{
Effect of Cooling Rate on Microstructure and Mechanical Properties of Thin-Walled Ductile Iron Castings
}

\author{
Marcin Górny and Edward Tyrała
}

\author{
(Submitted January 18, 2012; in revised form April 11, 2012; published online May 8, 2012)
}

\begin{abstract}
This article addresses the effect of cooling rate on microstructure and mechanical properties as determined by changing molding media and section size. The research was conducted for thin-walled iron castings with 2-5-mm wall thickness and for the reference casting with $13-\mathrm{mm}$ wall thickness, using different molding materials (silica sand and insulating sand "LDASC") to achieve various cooling rates. Thermal analysis was performed to determine the real cooling rate at the beginning of the graphite eutectic solidification. In general, it was found that the predictions based on theoretical analysis of the solidification process of ductile iron are in good agreement with the experimental outcomes. Finally, the present study provides insights into the effect of cooling rate on the graphite nodule count, the ferrite fraction and mechanical properties of thin-walled ductile iron castings. The study shows that the cooling rate of thin-walled castings varies in a wide range $\left(80-15{ }^{\circ} \mathrm{C} / \mathrm{s}\right)$ when changing the wall thickness from 2 to $5 \mathrm{~mm}$, accompanied by significantly changing the mechanical properties of ductile iron. The cooling rate can be effectively reduced by applying an insulating sand to obtain the desired properties of thin-walled castings practically in the whole range of ductile iron grades in accordance with the ASTM Standard.
\end{abstract}

Keywords cooling rate, ductile iron, structure

\section{Introduction}

The main factors that influence the structure of ductile iron are chemical composition, cooling rate, liquid treatment, and heat treatment (Ref 1-4). The cooling rate of a casting is primarily a function of its section size, pouring temperature, and the material mold ability to absorb the heat. Increasing the cooling rate significantly influences the as-cast structure (refines both the graphite size and matrix structure) and therefore the mechanical properties and increase the chilling tendency, which result in a higher hardness, decrease the strength and castings machinability can be severely impaired. The as-cast microstructure is governed by the solidification process and also by the subsequent eutectoid transformation. The inoculation practice and the cooling rate control the nodule count, while the matrix microstructure depends on the conditions under which the eutectoid reaction occurs ( $\operatorname{Ref} 5,6)$. Among the variables that influence the mechanism of the eutectoid reaction are the chemical composition, the cooling rate through the eutectoid temperature range, and the nodule count (Ref 7-9).

The issue of obtaining thin-walled castings is not simple, because it is associated with a wide range of cooling rates at the beginning of graphite eutectic solidification (Ref 10,11). The literature provides limited data on the cooling rate-structure relations, which is crucial in the property formation of thinwalled castings. This article presents an analysis of changes in

Marcin Górny and Edward Tyrala, AGH-University of Science and Technology, Reymonta Str. 23, 30-065 Krakow, Poland. Contact e-mail: mgorny@agh.edu.pl. the cooling rate of thin-walled castings with different wall thicknesses and using various molding materials and demonstrates its significant impact on the structure and mechanical property formation of ductile iron.

\section{Experimental}

The experimental melts were done in an electric induction furnace of intermediate frequency in a $15 \mathrm{~kg}$ capacity crucible. The furnace charge consisted of the following materials: Sorelmetal, technically pure silica, Fe-Mn, and steel scrap. After metal heating to a temperature of $1490{ }^{\circ} \mathrm{C}$, the bath was held for $2 \mathrm{~min}$ and then, the spheroidization and modification operations were performed by a bell method. For the spheroidization, the foundry alloy $\mathrm{Fe}-\mathrm{Si}-\mathrm{Mg}(6 \% \mathrm{Mg})$ in an amount of 1.5 wt. $\%$ was used, while the inoculation was done by means of the Foundrysil inoculant in an amount of $0.5 \mathrm{wt} . \%$. The pouring temperature was $1400{ }^{\circ} \mathrm{C}$. The cast iron was poured into plate-shaped molds with dimensions: $2 \times 50 \times 200 \mathrm{~mm}$, $3 \times 50 \times 200 \mathrm{~mm}, 5 \times 50 \times 200 \mathrm{~mm}$, and reference casting: $13 \times 50 \times 200 \mathrm{~mm}$. Silica sand ( $1 \mathrm{~K}$ of a fraction $100-200 \mu \mathrm{m})$ and urea-furfuryl resin Kaltharz 404U (1.3 wt.\%) with a hardener from a group of paratoluenesulfonic acids $100 \mathrm{~T} 3$ (0.5 wt.\%) were used, and the foundry molds were made using a paddle mixer (Ms-017A). In addition, LDASC sand, which has a much lower material mold ability to absorb the heat than silica sand (Ref 12), was used. The foundry mold with the LDASC sand was prepared in an analogous manner to the silica sand. In addition, they were instrumented with $\mathrm{Pt} / \mathrm{PtRh} 10$ thermocouples in a diameter of $0.1 \mathrm{~mm}$ for plates with 2 and $3-\mathrm{mm}$ wall thicknesses and in diameter of $0.3 \mathrm{~mm}$ for plates of other thicknesses entering a two-hole $\mathrm{Al}_{2} \mathrm{O}_{3}$ tube. The thermocouple tips were located in the geometrical center of each mold 
cavity normal to the heat transfer flow to improve the measurement accuracy. An Agilent 34970A electronic module was employed for numerical temperature recording.

Chemical composition of the investigated ductile iron was as follows: $\mathrm{C}-3.64-3.71 \%$; $\mathrm{Si}-2.65-2.69 \% ; \mathrm{Mn}-0.40-$ $0.44 \% ; \mathrm{P}-0.05 \%$; S- $0.010 \%$; $\mathrm{Cr}-0.03-0.04 \%$; Mg-0.043$0.047 \%$; and $\mathrm{Cu}-0.02 \%$.

Metallographic characterization was made on samples cut from plates and the average nodule count (average number of graphite nodules per unit area), $N_{\mathrm{F}}$ and matrix were measured using a Leica QWin v 3.5 quantitative analyzer at $\times 200$.

Strength testing was carried out on a flat samples (in accordance with ASTM E8M Standard) by means of the Zwick/ Roell Z050 device equipped with the Macro extensometer. The examination rate was $0.008 \mathrm{~s}^{-1}$. Specimen dimensions are as shown in Fig. 1.

\section{Results and Discussion}

\subsection{Thermal Analysis}

Below in Fig. 2 there are shown cooling curves of the investigated iron castings.

In Fig. 2, the equilibrium graphite eutectic solidification temperature $\left(T_{\mathrm{s}}\right)$ and the cementite eutectic-forming temperature $\left(T_{\mathrm{c}}\right)$ are marked, which were determined on the basis of dependence (Ref 13):

$T_{\mathrm{e}}=1153.90+5.25 \mathrm{Si}-14.88 \mathrm{P}$

$T_{\mathrm{c}}=1130.56-4.06(\mathrm{C}-3.33 \mathrm{Si}-12.58 \mathrm{P})$

$T_{\mathrm{c}}$ (Eq 2) is considered as the transition temperature for the solidification of cementite eutectic from graphite eutectic, or the chill-formation temperature (Ref 14). From Fig. 2, it can be

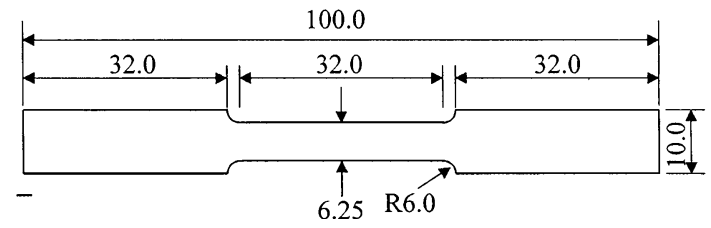

Fig. 1 Dimensions of mechanical tensile specimen

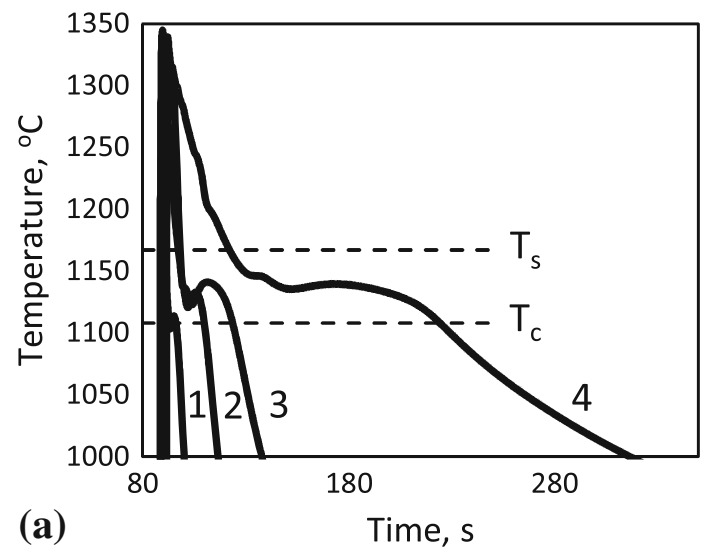

observed that as the wall thickness decreases (cooling rate increases), minimal temperature at the onset of graphite eutectic solidification $\left(T_{\mathrm{m}}\right)$ decreases within the temperature range $\Delta T_{\mathrm{sc}}=T_{\mathrm{s}}-T_{\mathrm{c}}$, where graphite eutectic is the only growing structure (without chills).

On the basis of thermal analysis, the cooling rates $(Q)$ near the equilibrium graphite eutectic solidification temperature $\left(T_{\mathrm{s}}\right)$ were determined. Figure 3 shows an example of the cooling curve of ductile iron, together with the corresponding cooling rate curve.

It is well known that the section sensitivity of ductile iron is lower than in gray iron, which contributes to the homogeneity of the structure of castings. However, in the case of thin-walled castings, section sensitivity of ductile iron should be taken into consideration because of the entry to the high cooling rate range (Ref 10). This contributes to a greater tendency of defect formation, especially inhomogeneity of the structure and the presence of chills. From the theoretical analysis of the solidification process of ductile iron (Ref 14), the cooling rate can be expressed in the following form:

$Q=\frac{8 T_{\mathrm{s}} a^{2}}{\pi c^{2} s^{2} \ln \frac{T_{\mathrm{i}}}{T_{\mathrm{s}}}}$

where $a$ is the material mold ability to absorb the heat, $T_{\mathrm{s}}$ is the equilibrium temperature of graphite eutectic, $c$ is the

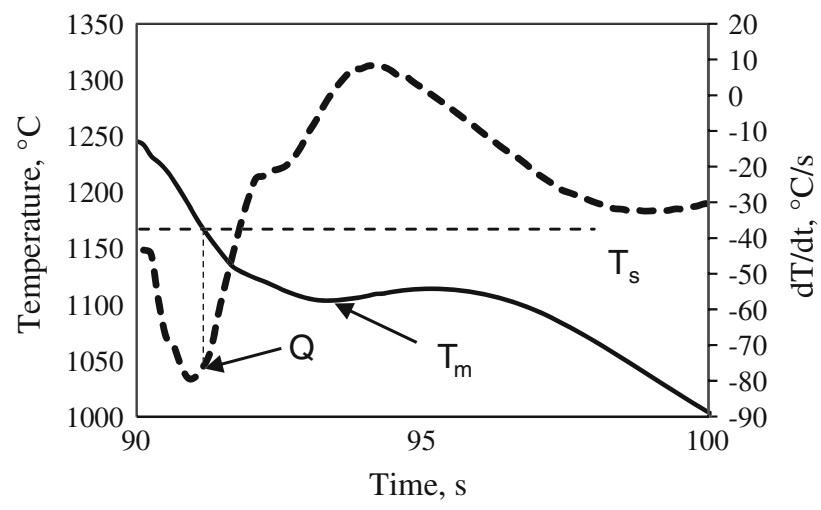

Fig. 3 Cooling curve (solid line) and cooling rate curve (dotted line) for ductile iron in 2-mm wall thickness (heat no. 1) $Q$ - cooling rate of ductile iron at the onset of graphite eutectic solidification, $T_{\mathrm{m}}-$ minimal temperature at the onset of graphite eutectic solidification

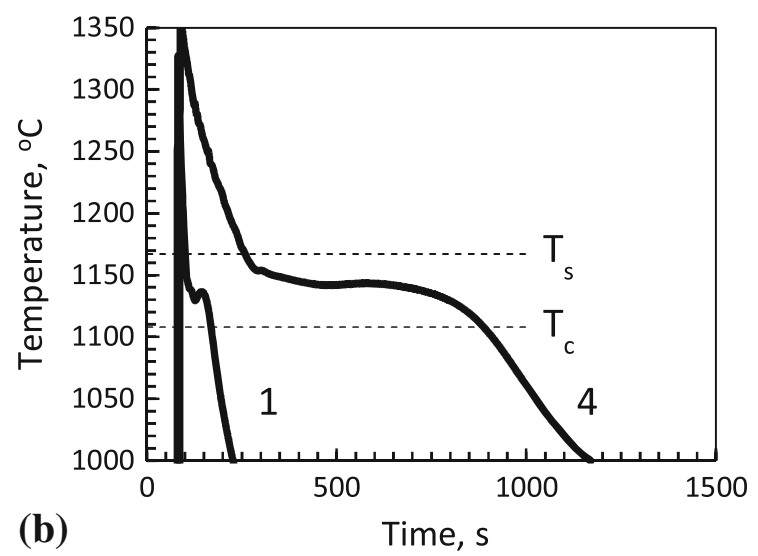

Fig. 2 Cooling curves of ductile iron in samples with different wall thicknesses: (a) heat no. 1: foundry mold with the silica sand (SMS), (b) heat no. 2: foundry mold with the LDADC sand. Wall thickness: $1-2 \mathrm{~mm} ; 2-3 \mathrm{~mm} ; 3-5 \mathrm{~mm}$; and $4-13 \mathrm{~mm}$ 
specific heat of cast iron, $s$ is the wall thickness of casting, and $T_{\mathrm{i}}$ is the initial temperature of the metal in the mold cavity just after pouring.

Figure 4 shows the cooling rate calculated from Eq 3 together with experimental data obtained from thermal analysis.

From this figure, a good agreement is noted between the theoretical prediction and the experimental outcome. From the theoretical analysis (Eq 3), it is shown that the cooling rate (except for wall thickness of the casting) is mainly affected by

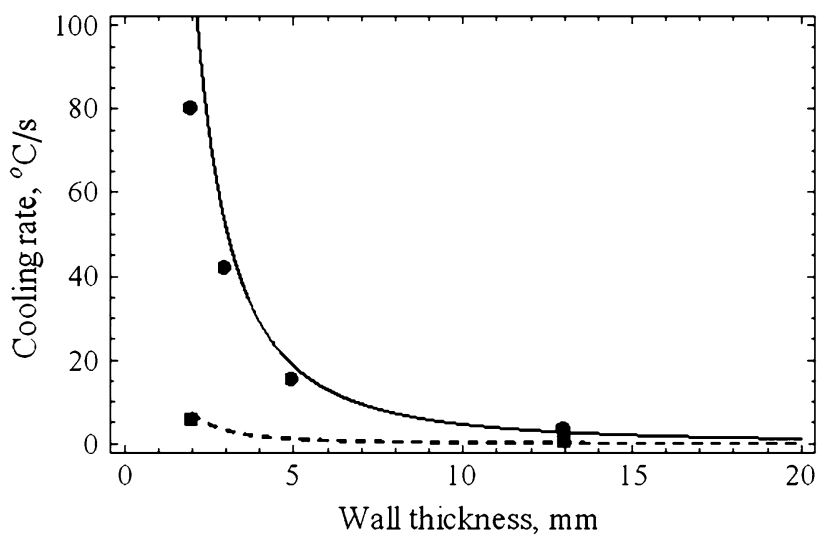

Fig. 4 Effect of wall thickness on the cooling rate of the casting: solid curve - melt no. 1 (Calculations were performed for the following data: $c=5.95 \mathrm{~J} \mathrm{~cm}^{-3} \mathrm{C}^{-1} ; T_{\mathrm{s}}=1167{ }^{\circ} \mathrm{C} ; T_{\mathrm{i}}=1400{ }^{\circ} \mathrm{C}$; and $a=$ $0.1 \mathrm{~J} /\left(\mathrm{cm}^{2} \mathrm{C} \mathrm{s}^{1 / 2}\right)$ ); dotted curve-melt no. 2 (Calculations were performed for the following data: $c=5.95 \mathrm{~J} \mathrm{~cm} \mathrm{C}^{-1} ; T_{\mathrm{s}}=1167{ }^{\circ} \mathrm{C}$; $T_{\mathrm{i}}=1400{ }^{\circ} \mathrm{C} ; \quad$ and $\left.a=0.025 \mathrm{~J} /\left(\mathrm{cm}^{2} \mathrm{C} \mathrm{s}^{1 / 2}\right)\right) ; \quad$ - experimental points for SMS mold, - - experimental points for LDASC mold the material mold ability to absorb the heat (a) and the initial temperature of the metal in a mold cavity close to the pouring temperature $\left(T_{\mathrm{i}}\right)$. Molding materials with a low coefficient of material mold ability to absorb the heat (e.g., LDASC sand) can significantly reduce the cooling rate. Calculations indicate that when changing silica sand $\left(a \approx 0.10 \mathrm{~J}^{\circ} \mathrm{C}^{-1} \mathrm{~cm}^{-2} \mathrm{~s}^{-1 / 2}\right)$ to LDASC sand $\left(a \approx 0.025 \mathrm{~J}^{\circ} \mathrm{C}^{-1} \mathrm{~cm}^{-2} \mathrm{~s}^{-1 / 2}\right)$, the cooling rate of thin-walled casting with a wall thickness of $2 \mathrm{~mm}$ decreases by more than 15 times. This is confirmed by experimental studies (Fig. 4). In general, it can be concluded that the use of molding materials with a low material mold ability to absorb the heat radically reduces the cooling rate. The analysis also shows that the cooling rates of thin-walled castings with a wall thickness of $2 \mathrm{~mm}$, obtained using LDASC sand, are at the level of what we achieve for castings with a wall thickness of $10 \mathrm{~mm}$ with silica sand (Fig. 4).

\subsection{Microstructure Characteristics}

Figure 5 shows the exhibited microstructures found in castings with different wall thicknesses and using different molding materials.

The cooling rate affects the maximum degree of undercooling at the beginning of graphite eutectic solidification and, consequently, the structure of iron (the number of graphite nodules, metal matrix). The figure below shows the results of the graphite nodule count as a function of cooling rate (in a wide range from 0.5 to $80{ }^{\circ} \mathrm{C} / \mathrm{s}$ ) for the two types of molding sand used together with the regression curve.

The number of graphite nodules as a function of cooling rate can be represented by the regression equation in the form of power series:

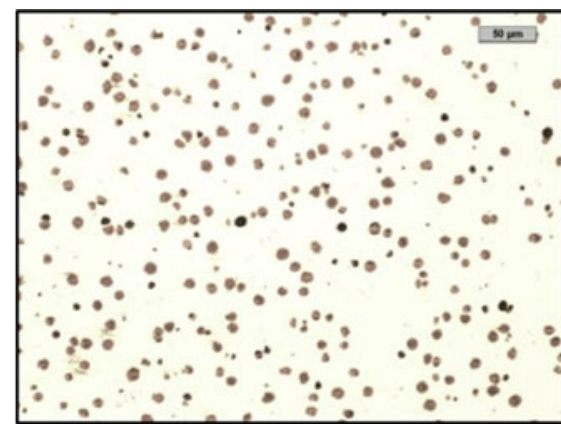

(a)

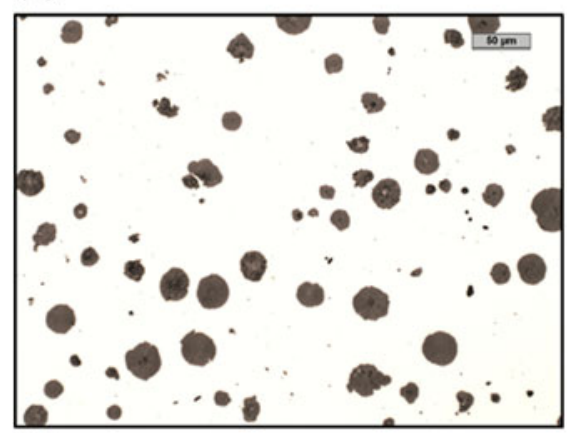

(d)

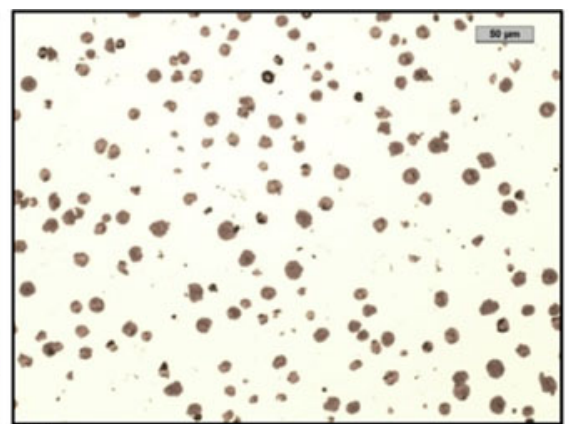

(b)

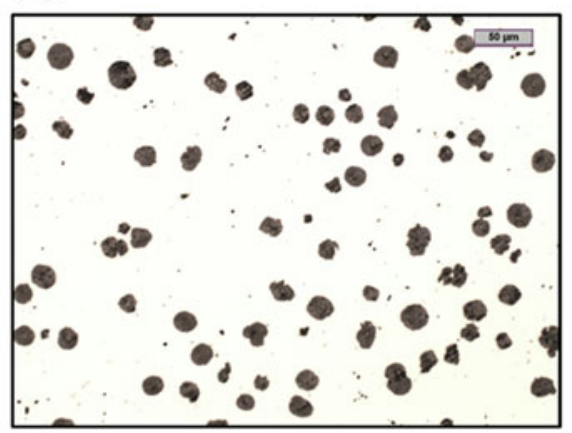

(e)

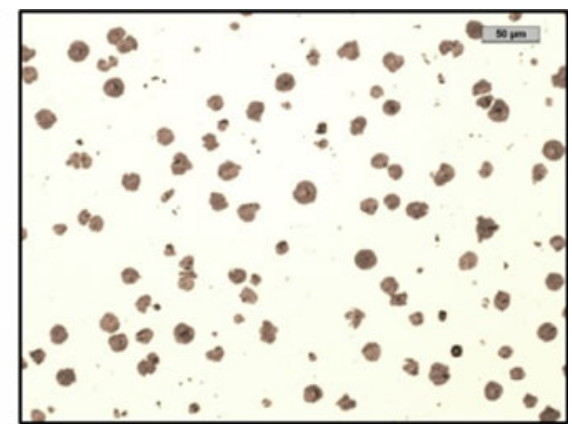

(c)

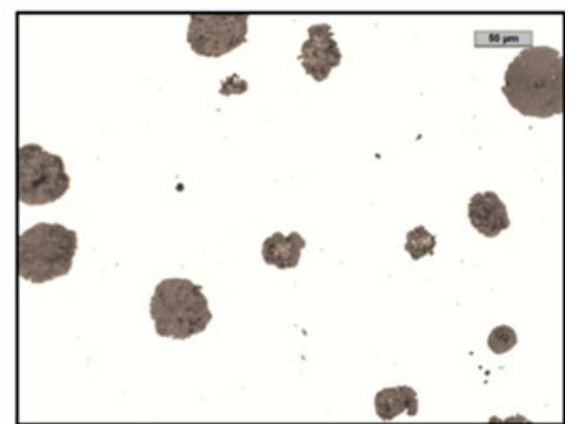

(f)

Fig. 5 Microstructure of ductile iron in castings with different wall thicknesses: (a) $2 \mathrm{~mm}$ (SMS mold), (b) $3 \mathrm{~mm}$ (SMS mold), (c) $5 \mathrm{~mm}$ (SMS mold) (d) $13 \mathrm{~mm}$ (SMS mold), (e) $2 \mathrm{~mm}$ (LDASC mold), and (f) $13 \mathrm{~mm}$ (LDASC mold). No etched samples 
$N_{\mathrm{A}}=143.95 Q^{0.56}$

where correlation coefficient amounts, $R=0.98$.

It is worth noting that despite the use of different molding materials, with a significantly different material mold ability to absorb the heat from each other, the graphite nodule count is in correlation with the cooling rate by Eq 4. The metallographic examination shows that the graphite nodule's count in thin-wall casting with a wall thickness of $2 \mathrm{~mm}$ LDASC sand is similar (Fig. 6) to the casting with wall thickness of $13 \mathrm{~mm}$ obtained using silica sand. These results are in conformity with the above-presented analysis of the effect of different molding materials on the cooling rate.

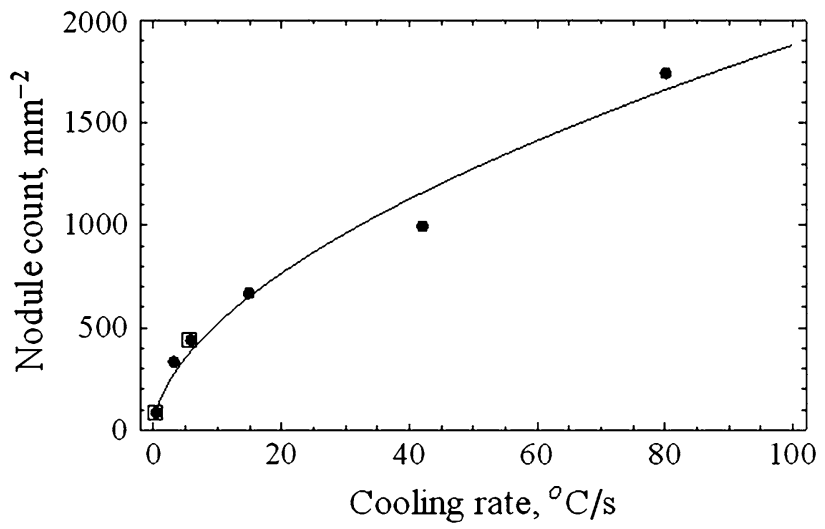

Fig. 6 Effect of cooling rate on the number graphite nodules. - - Experimental points for SMS mold, - - experimental points for LDASC mold
The cooling rate affects the graphite nodule's count, which is an important factor in forming the iron matrix. Figure 7 shows the changes found in castings microstructures with different wall thicknesses and using different molding materials, showing the changes in the ferrite fraction as a function of wall thickness, while Fig. 8 shows the results of metallographic examination.

The metallographic examination shows that reducing the wall thickness (increasing the cooling rate) reduces the ferrite fraction with a level of $90 \%$ for the casting wall thickness of $13 \mathrm{~mm}$ to $17 \%$ for the casting wall thickness of $2 \mathrm{~mm}$ (Fig. 8). In the investigated castings, chills were not detected.

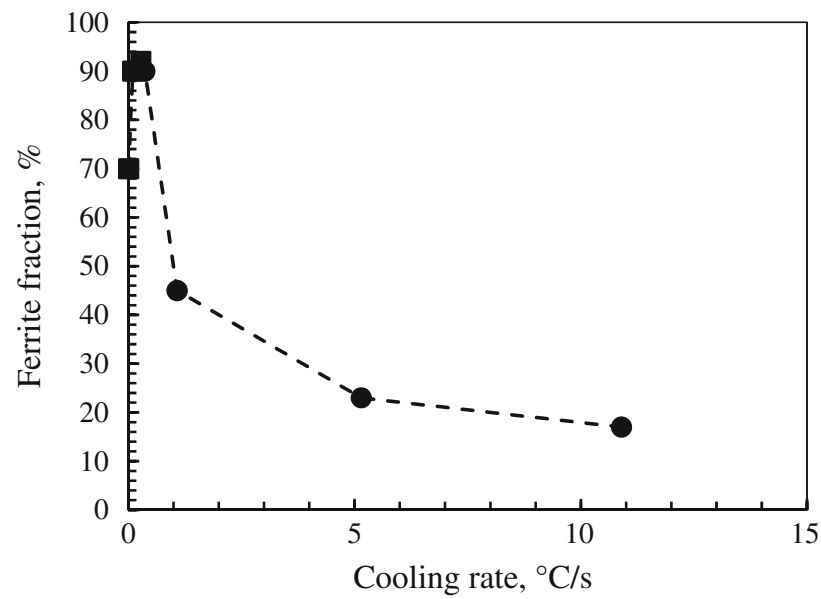

Fig. 8 Ferrite fraction as a function of cooling rate (near the equilibrium temperature of eutectoid transformation): - - experimental points for SMS mold, $\mathbf{\square}$ - experimental points for LDASC mold

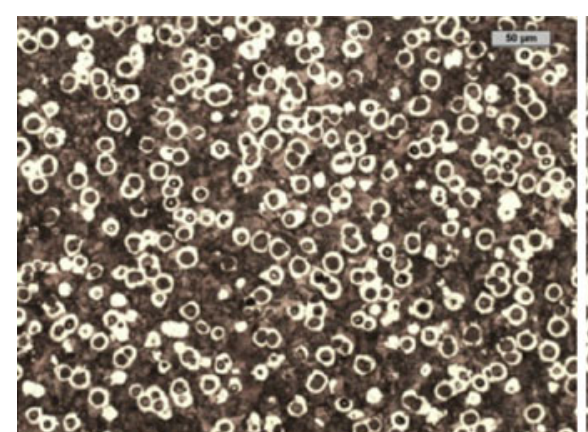

(a)

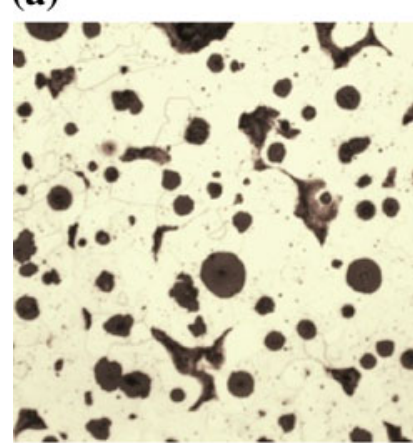

(d)

Fig. 7 Microstructure of ductile iron in castings with different wall thicknesses: (a) $2 \mathrm{~mm}$ (SMS mold), (b) $3 \mathrm{~mm}$ (SMS mold), (c) $5 \mathrm{~mm}$ (SMS mold) (d) $13 \mathrm{~mm}$ (SMS mold), (e) $2 \mathrm{~mm}$ (LDASC mold), and (f) $13 \mathrm{~mm}$ (LDASC mold). Nital etched samples

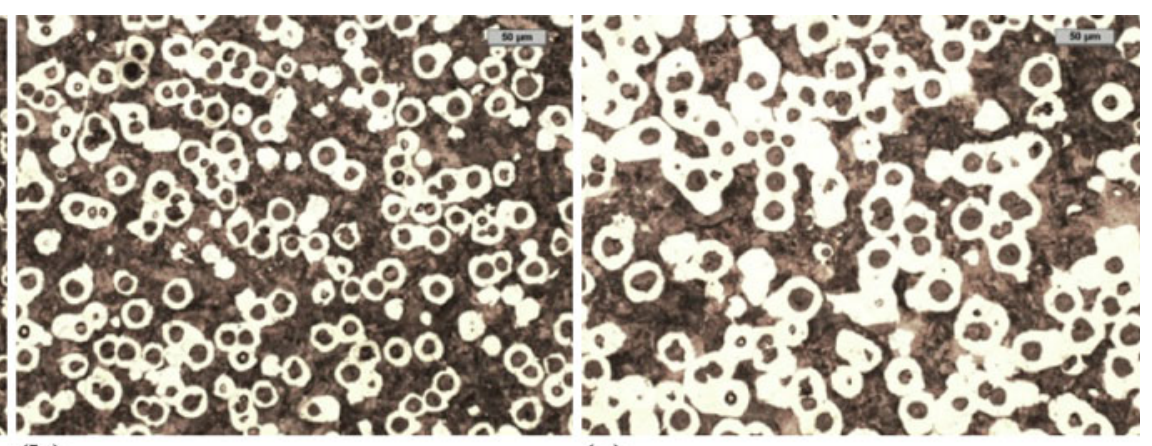

(b)

(c)

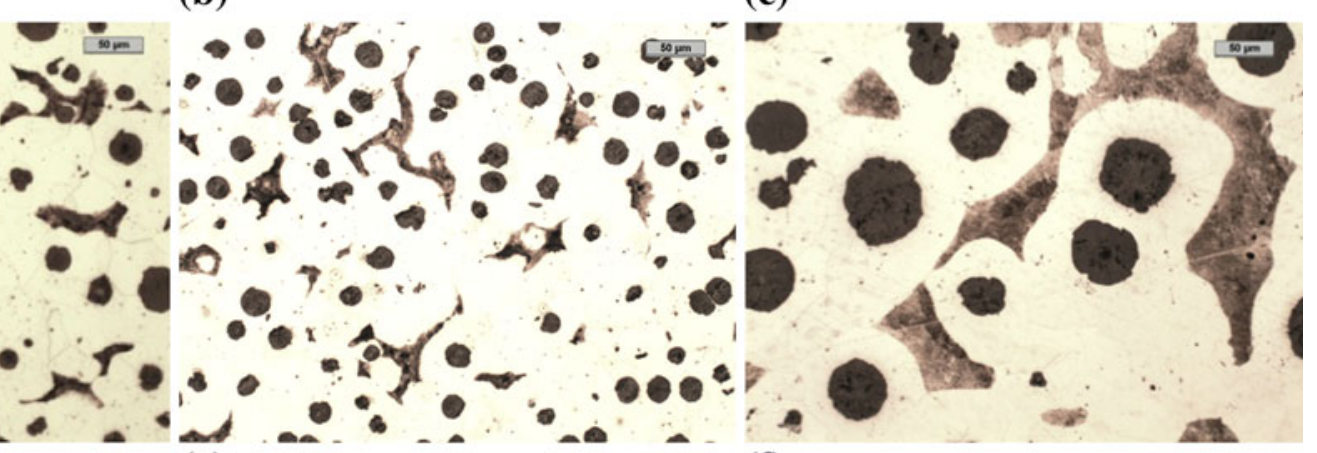

(f) 

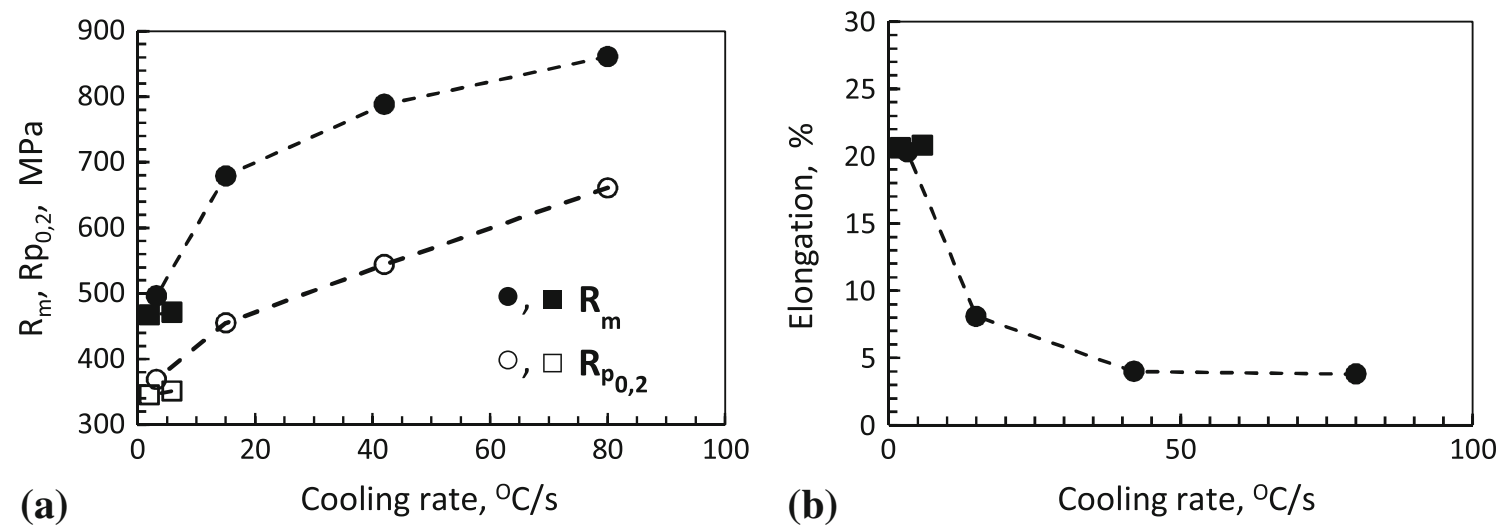

Fig. 9 Tensile and yield strength (a) and elongation (b) as a function of cooling rate $\bullet, \bigcirc$ experimental points for SMS mold, $\boldsymbol{\square}$, $\square$ —experimental points for LDASC mold

Matrix microstructure depends on the conditions under which the eutectoid reaction occurs. Among the variables that influence the mechanism of the eutectoid reaction are the chemical composition, the cooling rate through the eutectoid temperature range, and the nodule count. Replacement of silica sand by isolation sand (e.g., LDASC sand) in foundry mold resulted in a significant reduction in cooling rate (close to equilibrium eutectoid transformation temperature), which significantly increased the ferrite fraction in the matrix. The ferrite fraction in the cast with a wall thickness of $2 \mathrm{~mm}$ obtained by applying an insulating LDASC sand is similar to that obtained in the casting with a wall thickness of $13 \mathrm{~mm}$ using silica sand (Fig. 7 and 8). This is due to similar cooling rate $\left(Q_{2 \mathrm{~mm}-\mathrm{LDASC}}=0.28{ }^{\circ} \mathrm{C} / \mathrm{s}, Q_{13 \mathrm{~mm} \text {-sms }}=0.37^{\circ} \mathrm{C} / \mathrm{s}\right)$. As already mentioned, the use of insulation sand greatly reduces the cooling rate, thus reducing the number of graphite nodules. Reducing the number of graphite nodules when changing wall thickness from 2 to $13 \mathrm{~mm}$ using an insulating LDASC sand (Fig. 7e, f) reduces ferrite fraction in casting. This trend is associated with a significant increase in distance between the graphite nodules (an increase in austenite diffusion paths for carbon), which results in a greater pearlite fraction in the areas between the graphite nodules (Fig. 7f).

\subsection{Mechanical Testing}

The variation of the mechanical properties of samples as a function of cooling rate is presented in Fig. 9, while examples of tensile curves of castings with a wall thickness of $3 \mathrm{~mm}$, obtained using different molding materials in the stress-strain system, is shown in Fig. 10.

Experimental studies show that reducing the wall thickness of casting (increasing the cooling rate) causes substantial changes in mechanical properties. As regards thin wall castings (2-5 $\mathrm{mm})$, differences in tensile strength and elongation are observed, respectively: $\Delta R_{\mathrm{m}}=182 \mathrm{MPa}$ and $\Delta A=4.3 \%$, which means that castings may differ from the standpoint of classification according to Eq ASTM Standard. The use of insulating sand caused that, in thin-walled castings with a wall thicknesses of 2 and $3 \mathrm{~mm}$, the mechanical properties are in the same class as in the reference casting received in the silica sand mold (with a wall thickness of $13 \mathrm{~mm}$ ).

In summary, we can say that the cooling rate varies in a wide range $\left(80-15^{\circ} \mathrm{C} / \mathrm{s}\right)$ in thin-walled castings when changing the

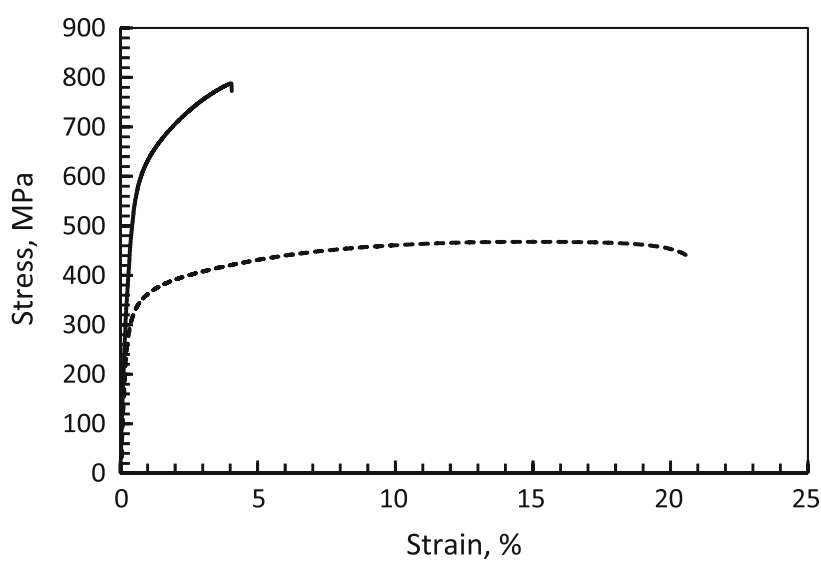

Fig. 10 Stress-strain curves of the castings with 3-mm wall thickness. Solid curve - casting obtained using SMS mold, dotted curvecasting obtained using LDASC mold

wall thickness from 2 to $5 \mathrm{~mm}$, accompanied by a significant change in the mechanical properties of ductile iron. It can be effectively reduced by applying insulating materials (e.g., LDASC sand), which gives the opportunity to form the structure of ductile iron, to obtain the desired properties of thin-walled castings practically in the whole range of grades provided in accordance with the ASTM Standard.

\section{Conclusion}

1. Theoretical calculations were made and then compared with the experimental outcome on cooling rate at the beginning of eutectic solidification. It was found that the predictions of the theoretical analysis (Eq 3) are in a good agreement with the experimental results.

2. In the preparation of thin-walled castings with a wall thickness of $2 \mathrm{~mm}$ using a sand LDASC, the cooling rate, the number of graphite nodules, ferrite fraction, and mechanical properties are at the level of what we achieve for castings with a wall thickness of the order of $13 \mathrm{~mm}$ made in molds with silica sand.

3. The cooling rate varies in a wide range $\left(80-15^{\circ} \mathrm{C} / \mathrm{s}\right)$ in thin-walled castings when changing the wall thickness 
from 2 to $5 \mathrm{~mm}$, accompanied by a significant change in the mechanical properties of ductile iron. It can be effectively reduced by applying an insulating material (e.g., LDASC sand), which gives the opportunity to form the structure of ductile iron, to obtain the desired properties of thin-walled castings practically in the whole range of grades provided in accordance with the ASTM Standard.

\section{Open Access}

This article is distributed under the terms of the Creative Commons Attribution License which permits any use, distribution, and reproduction in any medium, provided the original author(s) and the source are credited.

\section{References}

1. S.J. Karsay, Ductile Iron Production Practices, American Foundrymen's Society, Des Plaines, 1994, p 78-88

2. F.R. Salazar, M. Herrera-Trejo, M. Castro, J.N. Méndez, J.T. Torres, and M. Méndez, Effect of Nodule Count and Cooling Rate on As-Cast Matrix of a Cu-Mo Spheroidal Graphite, J. Mater. Eng. Perform., 1999, 8, p 325-329
3. P.J. Ratto, A.F. Ansaldi, V.E. Fierro et al., Low Temperature Impact Tests in Austempered Ductile Iron and Other Spheroidal Graphite Cast Iron Structures, ISIJ Int., 2001, 41, p 372-380

4. E. Fras and H.F. Lopez, A Theoretical and Experimental Study of the Dependence Between Undercooling and Nodular Eutectic Grains Density, Arch. Metall., 1998, 43, p 227-240

5. T. Skaland and O. Grong, Nodule Distribution in Ductile Cast Iron, AFS Trans., 1991, 99, p 153-157

6. D. Venugopalan, Prediction of Matrix Microstructure in Ductile Iron, AFS Trans., 1990, 98, p 465-469

7. E.N. Pan, W.S. Hsu, and C.R. Loper, Jr., Effects of Some Variables on the Matrix and Mechanical Properties of Ferritic Ductile Irons, AFS Trans., 1988, 96, p 645-660

8. S.K. Yu and C.R. Loper, Jr., The Effect of Molybdenum, Copper, and Nickel on the Pearlitic and Martensitic Hardenability of Ductile Cast Iron, AFS Trans., 1988, 96, p 8115-8118

9. J. Lacaze, C. Wilson, and C. Bak, Experimental Study of the Eutectoid Transformation in Spheroidal Graphite Cast Iron, Scand. J. Metall., 1994, 23, p 151-163

10. M. Górny, Structure Formation of Ultra-Thin Wall Ductile Iron Castings. Akapit Ed., Cracow, 2010, p 89-93 (in Polish)

11. E. Fraś, M. Górny, and H.F. Lopez, Thin Wall Ductile and Austempered Iron Castings as Substitutes for Aluminum Alloy Castings, Int. Foundry Res., 2009, 61, p 2-10

12. R.E. Showman, R.C. Aufderheide, and N. Yeomans, Ironing Out ThinWall Casting Defects, Mod. Cast., 2006, 96, p 29-32

13. B. Lux and W. Kurz, Solidification of Metals, vol. 110, The Iron and Steel Institute, London, 1967, p 193

14. E. Fraś, M. Górny, and H.F. Lopez, Eutectic Transformation in Ductile Cast Iron. Part I-Theoretical Background, Metall. Foundry Eng., 2005, 31, p 113-136 